\title{
Flexibility of neural stem cells
}

\author{
Eumorphia Remboutsika ${ }^{1}{ }^{*}$, Maximilianos Elkouris ${ }^{1}$, Angelo lulianella ${ }^{2 \dagger}$, Cynthia L. Andoniadou ${ }^{3+}$, \\ Maria Poulou' ${ }^{1+}$,Thimios A. Mitsiadis' ${ }^{4}$, Paul A. Trainor ${ }^{2,5}$ and Robin Lovell-Badge ${ }^{3}$ \\ 1 Stem Cell Biology Laboratory, Institute of Molecular Biology and Genetics, Biomedical Sciences Research Center "Alexander Fleming," Athens, Greece \\ 2 Stowers Institute for Medical Research, Kansas City, MO, USA \\ ${ }^{3}$ Division of Stem Cell Biology and Developmental Genetics, Medical Research Council National Institute for Medical Research, London, UK \\ ${ }^{4}$ Institute of Oral Biology, ZZM, Faculty of Medicine, University of Zurich, Zurich, Switzerland \\ ${ }^{5}$ Department of Anatomy and Cell Biology, University of Kansas Medical Center, Kansas City, KS, USA
}

Edited by:

Anna Petryk, University of Minnesota,

USA

Reviewed by:

Daniel Graf, University of Zurich

Switzerland

Catherine Ellen Krull, University of

Michigan, USA

${ }^{*}$ Correspondence:

Eumorphia Remboutsika, Stem Cell

Biology Laboratory, Biomedical

Sciences Research Center Alexander

Fleming, 34 Fleming Street, Vari-Attica

16672, Greece.

e-mail: remboutsika@fleming.gr

${ }^{t}$ Present address:

Angelo lulianella, University of

Dalhousie, Halifax, NS, Canada B3H

1X5;

Cynthia L. Andoniadou, Neural

Development Unit, University College

London Institute of Child Health, 30

Guilford Street, WC1N 1EH, London,

UK;

Maria Poulou, Department of Radiation

Oncology, David Geffen School of

Medicine at University of California Los

Angeles, 10833 Le Conte Avenue, Los

Angeles, CA 90094-1714, USA.
Embryonic cortical neural stem cells are self-renewing progenitors that can differentiate into neurons and glia. We generated neurospheres from the developing cerebral cortex using a mouse genetic model that allows for lineage selection and found that the self-renewing neural stem cells are restricted to Sox2 expressing cells. Under normal conditions, embryonic cortical neurospheres are heterogeneous with regard to Sox2 expression and contain astrocytes, neural stem cells, and neural progenitor cells sufficiently plastic to give rise to neural crest cells when transplanted into the hindbrain of E1.5 chick and E8 mouse embryos. However, when neurospheres are maintained under lineage selection, such that all cells express Sox2, neural stem cells maintain their Pax6 $6^{+}$cortical radial glia identity and exhibit a more restricted fate in vitro and after transplantation. These data demonstrate that Sox2 preserves the cortical identity and regulates the plasticity of self-renewing Pax6 $6^{+}$radial glia cells.

Keywords: radial glia, self-renewal, neural stem cell, stem cell niche, Sox genes, neurogenesis, gliogenesis, neural crest

\section{INTRODUCTION}

Sox genes encode transcriptional regulators with HMG box DNAbinding domains, and are involved in specifying cell fates (Kamachi et al., 2000; Scaffidi and Bianchi, 2001; Wilson and Koopman, 2002; Wegner and Stolt, 2005). Sox1, Sox2, and Sox3 (SoxB1 subfamily; Wood and Episkopou, 1999; Kamachi et al., 2000) are expressed broadly within the primitive neuroepithelium during embryogenesis and typically mark uncommitted precursors within the developing (Wood and Episkopou, 1999; Avilion et al., 2003) and adult central nervous system (CNS; Ferri et al., 2004; Brazel et al., 2005).

Gain of function experiments in the chick showed that SoxB1 factors maintain the neural progenitor (NP) state and inhibits differentiation of spinal cord precursors. In contrast, suppression of SoxB1 function leads to premature cell cycle exit and initiation of neuronal differentiation (Bylund et al., 2003; Graham et al., 2003; Kan et al., 2004; Sandberg et al., 2005). In mice, SoxB1 loss of function mutations failed to reveal the role of these genes in NSCs since they result in either early lethality (Sox2) or no obvious NSC phenotypes (Sox 1 and Sox3; Nishiguchi et al., 1998; Avilion et al., 2003; Malas et al., 2003; Rizzoti et al., 2004; Ekonomou et al., 2005). Recent findings suggested that Sox 1 maintains cortical NP cells undifferentiated by suppressing cell cycle exit to neurogenesis (Elkouris et al., 2011). Sox2 hypomorphic mouse mutants exhibit impaired neurogenesis in the adult brain together with neurodegeneration (Ferri et al., 2004). Similarly, conditional ablation of Sox 2 also caused defects in adult neurogenesis, particularly in hippocampal development and NSC maintenance which is sonic hedgehog (Shh) dependent (Favaro et al., 2009; Pevny and Nicolis, 2010). However, the precise role of Sox2 in embryonic NSCs is still elusive.

Cortical NSC can be cultured ex vivo as neurospheres which are heterogenous free-floating aggregates consisting of mixed populations of stem, progenitor, and differentiated cells. These cells eventually lose their regional identity in culture (Ellis et al., 2004; Brazel et al., 2005; Ahmed, 2009; Conti and Cattaneo, 2010), which raises important questions about the signals required for their maintenance and differentiation properties in vitro and in vivo. We used a mouse genetic model (Sox $2^{\text {Bgeo }}$ ) to investigate the molecular properties and the plasticity of a homogeneous population of cortical NSCs obtained by selection for Sox2 expression (Li et al., 1998; Zhao et al., 2004). 


\section{MATERIALS AND METHODS \\ MICE}

Sox $2^{\beta \text { geo/ } /+}$ and Sox $2^{\beta g e o 2 /+}$ were maintained and genotyped as previously described (Avilion et al., 2003; Ekonomou et al., 2005). All experiments carried out on mice were approved under the UK Animal (scientific procedures) Act (Project license 80/1949; National Institute for Medical Research), the Animals Act 160/03.05.1991/revised 86/609/EEC/24.11.1986 EU directive for Animal Experimentation (Prot. No. 767/28.02.07; BSRC"Alexander Fleming") and the IACUC animal welfare guidelines and approved protocols and licenses (Stowers Institute for Medical Research).

\section{NEUROSPHERE CULTURES}

Neurospheres were derived and maintained as previously described (Zappone et al., 2000; Elkouris et al., 2011). Cortices from Sox2 $2^{\beta \text { gseo/ }}$ mice at E14.5 were dissected in ice cold DMEM-F12 medium (GIBCO-BRL) supplemented with $2 \mathrm{mM}$ glutamine and antibiotics before they were triturated in DMEM-F12 medium containing $0.6 \%$ glucose, $9.6 \mathrm{mg} / \mathrm{ml}$ putrescine (SIGMA), $6.3 \mathrm{ng} / \mathrm{ml}$ progesterone (SIGMA), $5.2 \mathrm{ng} / \mathrm{ml}$ sodium selenite (SIGMA), $25 \mathrm{mg} / \mathrm{ml}$ insulin (SIGMA), $100 \mathrm{mg} / \mathrm{ml}$ transferrin (SIGMA), $20 \mathrm{ng} / \mathrm{ml}$ each of bFGF and EGF (R\&D systems), $2 \mathrm{mM}$ glutamine and antibiotics (NSC medium; Zappone et al., 2000). Cell suspensions were plated at clonal density $\left(10^{4}\right.$ cells $\left./ \mathrm{ml}\right)$ in NSC medium and primary neurospheres were grown and maintained in this medium for 3 weeks. When required, G418 was added at a final concentration of $250 \mathrm{mg} /$ $\mathrm{ml}$. $\beta$-galactosidase activity was assayed as described (Zappone et al., 2000; Elkouris et al., 2011). At 3 weeks, $\beta$-galactosidase ${ }^{+}$cells were present as isolated cells ( $<2 \%$ of cells), in coherent patches $(2-50 \%$ of cells) or dispersed throughout ( $>50 \%$ of cells) in $3-5,5-7$, and approximately $90 \%$ of Sox $2^{\beta g e o / /}$ neurosphere cultures, respectively. For differentiation, single neurospheres were plated on a matrigel support and allowed to differentiate for 10 days. For the FACS analysis, Sox $2^{\beta g e o / t}$ neurospheres were dissociated and single cells were incubated with CMFDG substrate (Molecular Probes) for $30 \mathrm{~min}$ on ice according to the instructions of the manufacturer, before they were subjected to cell sorting for $\beta$-galactosidase activity on a MoFlo cell sorter (Cytomation). Sox2 $2^{+}\left(\mathrm{LacZ}^{+}\right)$and Sox2- $\left(\mathrm{LacZ}^{-}\right)$ cells were cultured as single cell suspension in serial dilutions and allowed to form neurospheres in the absence of G418 selection.

\section{IMMUNOHISTOCHEMISTRY}

Immunohistochemistry was performed on differentiated cells fixed with $100 \%$ methanol. Whole-mount immunofluorescence was performed on live (RC2 staining) and either methanol or MEMFA (Avilion et al., 2003) fixed neurospheres. On average about 10 neurospheres were used per individual experiment with two to seven replicates. Antibody incubation was generally performed in phosphate buffered saline (PBS) solution containing $1 \% \mathrm{BSA}, 0.15 \%$ glycine, and $0.1 \%$ Triton-X100 at $4^{\circ} \mathrm{C}$ overnight or for $1-2 \mathrm{~h}$ at room temperature. Images from intact neurospheres with representative staining were recorded on a Leica TCS SP confocal microscope using the TCSNT software.

\section{ANTIBODIES}

Primary antibodies were: anti-Sox2 (rabbit purified IgG; 1:2500, R. Lovell-Badge); anti-Pax6 (mouse IgG 1:500; Chemicon); antinestin (mouse IgG 1:75; DSHB); anti-GFAP, Cy3-linked (mouse
IgG 1:100; SIGMA); mouse RC2 (mouse IgM 1:100; DSHB); antiBIII tubulin (TuJ1; mouse IgG 1:1000; BabCo); anti-Sox9 (rabbit purified IgG 4796; 1:1000; a gift from S. Guioli); and anti-Sox10 (mouse IgG 1:10; a gift from D. Anderson). AlexaFluor 488, 594, 555 , and 647 chromophores were used with secondary antibodies (Molecular Probes). Photographs were acquired with Leica SP2 (NIMR, London) and SP5 (BFRAA, Athens) confocal microscopes using ALasAF Software (Leica).

\section{NEUROSPHERE TRANSPLANTATIONS AND MOUSE AND CHICK EMBRYO CULTURE}

Neurospheres were removed from culture and labeled by incubation in Dil labeling solution $(0.05 \% \mathrm{w} / \mathrm{v}$ Dil in $0.3 \mathrm{M}$ sucrose stock, diluted 1:1 in DMEM) for up to $5 \mathrm{~min}$. Neurospheres were then washed multiple times in DMEM (for mouse transplants) or Ringer's solution (for chick embryos). Depending on their size, neurospheres were either dissected into smaller pieces using glass needles for transplantation into mouse embryos or in the case of chick embryos they were transplanted as whole neurospheres at the levels of rhombomere (r) 2 and $\mathrm{r} 4$ in the hindbrain.

Mouse embryos were collected from timed pregnant CD1 mice at $8.5 \mathrm{dpc}$ for in vitro whole embryo culture. Following dissection of conceptuses from the uterus, the parietal yolk sac was removed leaving the embryo with an intact visceral yolk sac amnion and ectoplacental cone. Post neurosphere transplantation with $0.30 \mu \mathrm{m}$ glass needles, mouse embryos were cultured in DMEM culture medium supplemented with $50 \%$ rat serum, L-glutamine and penicillin/streptomycin (DR50) for $24 \mathrm{~h}$ in small glass bottles attached to a rotating drum (BTC engineering, Cambridge) at $37^{\circ} \mathrm{C}$ with a constant atmosphere of $5 \% \mathrm{O}_{2}, 5 \% \mathrm{CO}_{2}, 90 \% \mathrm{~N}_{2}$ (Sturm and Tam, 1993).

Fertilized chick eggs were incubated for approximately $36 \mathrm{~h}$ at $37^{\circ} \mathrm{C}$ in a humidified incubator to obtain embryos of the eight somite stage or earlier. Individual eggs were windowed and the embryos were visualized via injection of India Ink (1:10 dilution in Ringer's Solution). The vitelline membrane covering the hindbrain was opened using tungsten needles after which a small slit was made in the midline of the neural tube at the desired axial level in the hindbrain. Post neurosphere transplantation, host chick embryo eggs were resealed with clear tape and returned to a $37^{\circ} \mathrm{C}$ incubator for either $24-48$ h or up to 8-9 days.

\section{ELECTROPORATION AND IN SITU HYBRIDIZATION}

Chick embryos with eight or less somites were obtained as described above. Control plasmid $p C M V-G F P$ was injected alone or together with $p C M V$-mouseSox 2 or pCMV-mouseSox 9 into the cranial neural tube with finely pulled injection needles. Then $0.5 \mathrm{~mm}$ gold electrodes ( $0.5 \mathrm{~cm}$ separation) were placed gently on the vitelline membrane on either side of the cranial neural tube and the plasmids were electroporated into the neuroepithelium using the following conditions: 5 pulses of a $25-\mathrm{V}, 50 \mathrm{~ms}$ wave with a 1-s gap between pulses. After electroporation, host chick embryo eggs were resealed with clear tape and returned to a $37^{\circ} \mathrm{C}$ incubator for up to $24 \mathrm{~h}$. Electroporated chick embryos were then processed for in situ hybridization as previously described (Wilkinson and Nieto, 1993; Wilkinson, 1995) with mouse Sox2 and chick Sox10 cRNA probes. 


\section{RESULTS}

\section{NSC SELF-RENEWAL REQUIRES Sox2 EXPRESSION}

To analyze the properties of Sox $2^{\beta g e o /+}$ NSC, we cultured neuroepithelial cells from the cerebral cortex of individual E14.5 heterozygous mouse embryos for 3 weeks as primary neurospheres (Zappone et al., 2000) in two distinct populations, either without

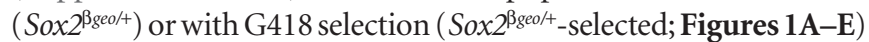
without sub-cloning (Figures 1F-L). Wild type $(w t)$ cells were also used as controls for any in vitro effects related to Sox2 heterozygosity (Figure 1A). No significant differences were observed between $w t$ and Sox $2^{\beta g e o / /}$ neurospheres. So $x 2^{\beta g e o / /}$ neurospheres had mosaic and variable patterns of lacZ activity reflecting Sox2-expressing cells, ranging from dispersed single cells (Figure 1B), to patches (Figure 1C), to a majority of Sox $2^{+}$cells (Figure 1D), a heterogeneity similar to adult NSC cultures (Brazel et al., 2005; Machon et al., 2005). In contrast, in Sox $2^{\beta \text { ggeo/ }}$-selected neurospheres, a homogene-
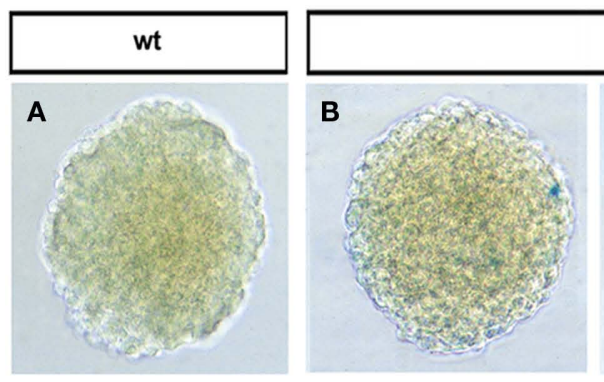

\section{Sox $2^{\beta g e o /+}$}

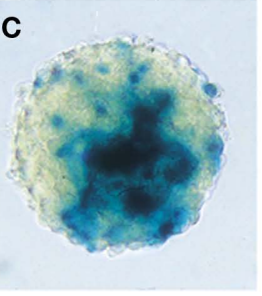

\section{Sox $2^{\mathrm{Bgeo/+}}$-selected}

E
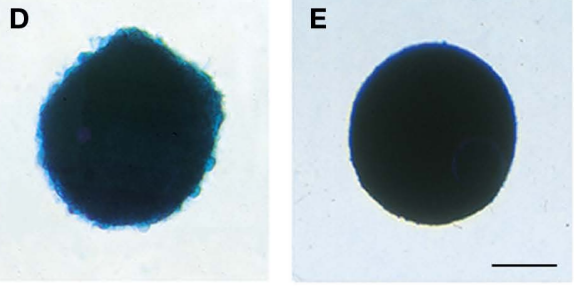

F

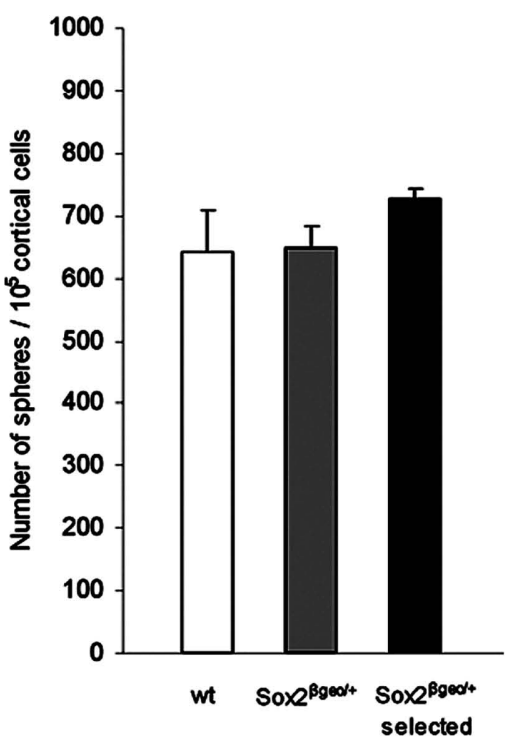

G
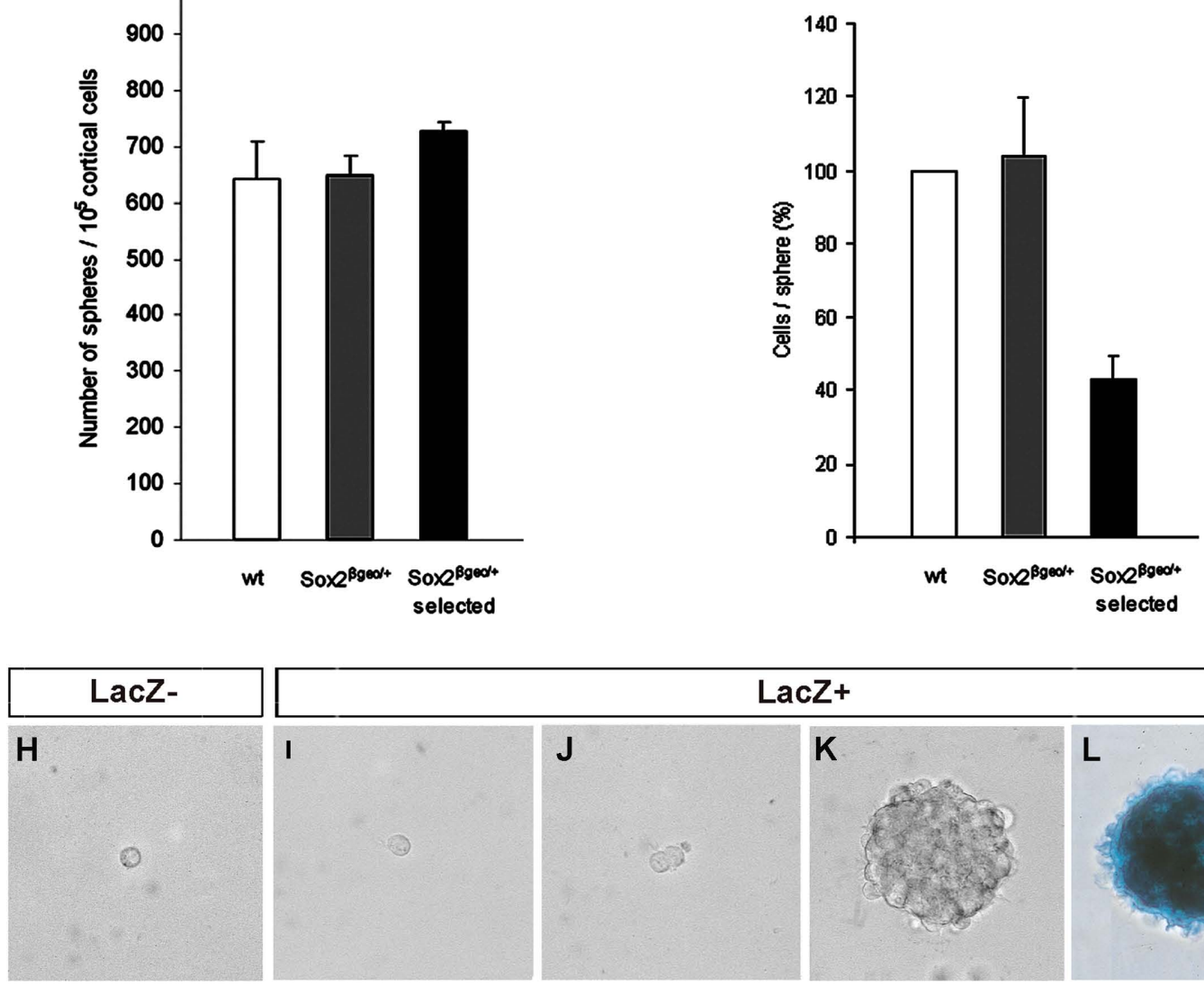

\section{LacZ+}
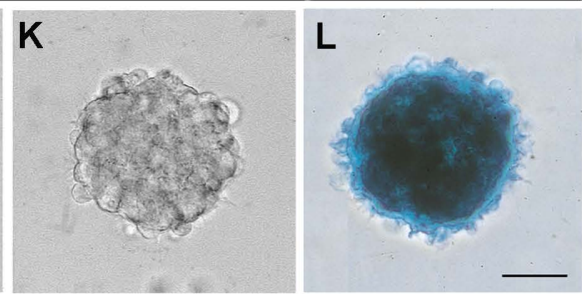

FIGURE 1 | Cortical neurospheres contain stochastic numbers of Sox2expressing self-renewing cells. $\beta$-galactosidase activity in $w t$ (A), Sox $2^{\beta \text { geo/ }}$ (B-D), and Sox $2^{\text {Bgeo/ }}$-selected (E) neurospheres cultured for 3 weeks. Cortical neuroepithelial cells from E14.5 Sox $2^{\text {Bgeo/4 }}$ embryos were grown either without

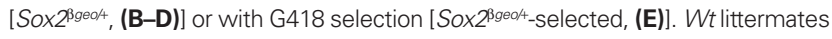
were used as a control [(A); scale bar $=50 \mu \mathrm{m}]$. Numbers of neurosphereforming cells were similar for $w t$, Sox $2^{\beta \text { geo/ }}$, and Sox $2^{\beta g e o /}$-selected cells (F), but

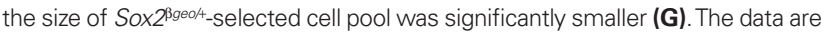
presented as the mean \pm SD $(\mathbf{H}, \mathbf{I})$. Sox $2^{\text {Bgeo/ } /}$ neurospheres were dissociated and fractionated into Sox $2^{\text {Bgeo/- }}$-expressing $\left[(\mathbf{I}), \mathrm{LacZ}^{+}\right]$and non-expressing cells $[(\mathbf{H})$, LacZ'] using FACS. Each cell population was cultured at clonal density $\left(10^{4}\right.$ cells/ $\mathrm{ml}$ ) and allowed to proliferate ( $\mathbf{J}$ ) without selective pressure. Only Sox $2^{\beta g e o / 4}$ expressing cells generated neurospheres (K) expressing variable levels of $\beta$-galactosidase activity [(L); scale bar $=50 \mu \mathrm{m}]$. 
ous population of Sox $2^{+}$cells was obtained (Figure 1E, Sox $2^{\text {Bgeo/ }}$ selected). These neurospheres were smaller and contained $40 \%$ of the number of cells present in $w t$ and So $x 2^{\beta \text { geo/t }}$ neurospheres. Since the original numbers of neurosphere-forming cells were similar for $w t$, So $x 2^{\beta g e o /+}$, and Sox $2^{\beta g e o /+}$-selected cultures (Figure 1F), the cells that failed to express Sox 2 were eliminated by selection.

To determine which cells were capable of self-renewal, we tested the ability of Sox $2^{-}$and Sox $2^{+}$cells to give rise to secondary neurospheres (Figures $\mathbf{1 H}-\mathbf{L}$ ). FACS sorting for $\beta$-galactosidase expression separated the two cell populations present in dissociated unselected Sox $2^{\text {Bgeo// }}$ neurospheres. When each fraction was cultured at clonal density in serial dilutions, no neurospheres were produced from the Sox $2^{-}$cells, which did not survive beyond $12-24 \mathrm{~h}$ in culture (Figure 1H). Only So $x 2^{+}$cells divided (Figures 1I,J) and gave rise to secondary neurospheres (Figure $1 \mathbf{K}$ ). On average, about $1 \%$ of the cells exhibited the ability to generate secondary neurospheres. As observed for the primary neurospheres (Figures 1B-D), the majority of cells within the secondary neurospheres expressed Sox2 (Figure 1L). Thus, self-renewing NSCs are restricted to Sox2expressing cells.

\section{NSCs REQUIRE Sox2 EXPRESSION TO MAINTAIN THEIR Pax6 ${ }^{+}$RG IDENTITY IN NEUROSPHERE CULTURES.}

Radial glia ( $R G$ ) comprise the predominant form of NP cells in the E14.5 cortex (60-70\%; Gotz et al., 2002; Gotz, 2003; Malatesta et al., 2003; Gotz and Barde, 2005). These cells exhibit self-renewal properties and multipotency (Campbell and Gotz, 2002; Gotz et al., 2002; Gotz, 2003; Gotz and Barde, 2005) and express the nestin-linked epitope RC2 (Malatesta et al., 2003; Mori et al., 2005; Figure 2A). $\mathrm{RC}^{+}$cells co-express Sox 2 in the proliferating zones of the cortex and in cell spreads (Figure 2A and inset photo). Mitogens can change the character of cells in culture and as a result neurosphere assays may not reflect the endogenous progenitor state and fate of the cortical environment in vivo ((Brazel et al., 2005; Jensen and Parmar, 2006; Conti and Cattaneo, 2010) We, therefore, examined the ability of cortical Sox $2^{+}$cells to maintain their in vivo identity in neurosphere cultures.

Primary neurospheres from So $x 2^{\beta g e o /+}$ embryos were cultured with or without selection (Figures $2 \mathbf{B}-\mathbf{E}$ ) and characterized for neural markers (Figures 2C,Di-Xv). To exclude the possibility that some of the cellular phenotypes could arise from Sox2 heterozygosity, neurospheres produced from $w t$ littermates were also analyzed. Wt and Sox $2^{\beta g e o /+}$ neurospheres were heterogeneous with respect to Sox $2^{+}$and nestin ${ }^{+}$cells (Figures $2 \mathrm{Ci}, \mathbf{i i}, \mathbf{i v}, \mathbf{v}$ ). In contrast, Sox $2^{\text {Bgeo/t }}$-selected neurospheres comprised of Sox $2^{+}$nestin ${ }^{+}$cells (Figures 2Ciii,vi) and showed suppressed astrogenesis as evidenced by the reduction in numbers of $\mathrm{GFAP}^{+}$cells and in levels of GFAP staining (Figure 2Dxviii) when compared to control neurosphere populations (Figures 2Dxvi,xvii). Wt and Sox $2^{\beta g e o /+}$ neurospheres contained high numbers of Sox $9^{+}$cells (Figures 2Dxiii,xiv) and as Sox9 is implicated in the change of competence of neuroepithelial cells to generate glial lineages (Wegner and Stolt, 2005), the high

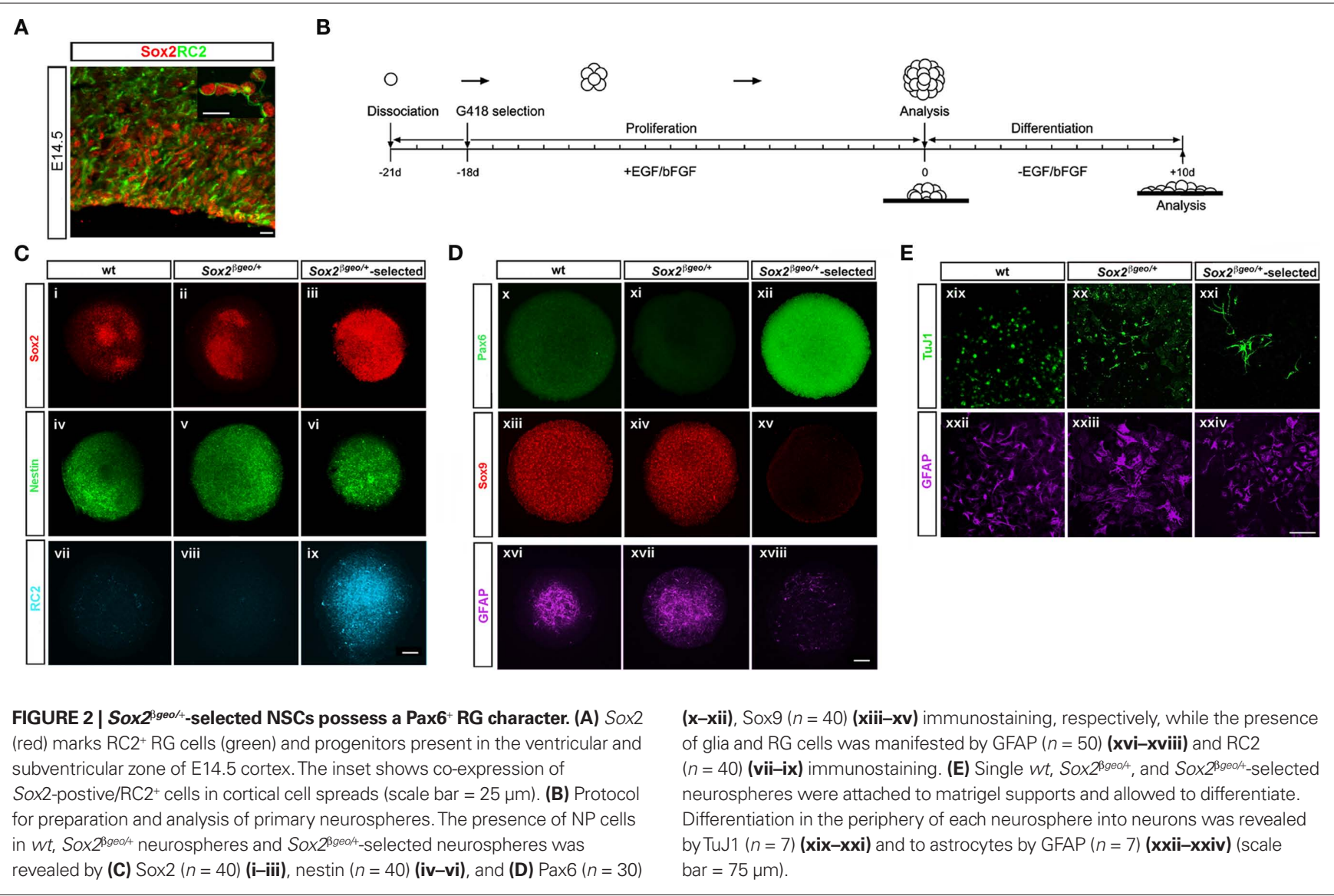


number of astrocytes could be due to the presence of Sox $9^{+}$cells. Sox $9^{+}$levels were severely reduced in Sox $2^{\text {Bgeo/t+}}$-selected neurosphere cells (Figure 2Dxv). Given the clonal origin of the neurospheres (Zappone et al., 2000), and the fact that these arise from the Sox $2^{+}$ fraction (Figures $\mathbf{1 K}, \mathbf{L}$ ), it is most likely that the Sox $9^{+}$cells are descendents of the Sox $2^{+}$cells (Gotz and Barde, 2005). Wt and So $x 2^{\beta g e o /+}$ neurospheres contained few $\mathrm{RC} 2^{+}$cells (Figures 2Cvii,viii). In contrast, we found that the So $\times 2^{\beta g e o /+}$-selected neurospheres were comprised of $\mathrm{RC}^{+}$cells (Figure $2 \mathrm{Cix}$ ). Moreover, these $\mathrm{RC}^{+}$cells maintain their cortical identity by expressing high levels of Pax6 protein (Figure 3Dxii), when compared to $w t$ and Sox $2^{\text {Bgeo/+ }}$ neurospheres (Figures 2Dx,xi). Collectively, these data demonstrated that cortical NSCs depend on homogeneous Sox2 expression to maintain their Pax6 ${ }^{+}$RG identity ex vivo.

Radial glia cells differentiate into neurons and glial cells later in development (Gotz et al., 1998; Malatesta et al., 2000; Campbell and Gotz, 2002; Gotz et al., 2002; Gotz, 2003; Kriegstein and Gotz, 2003; Malatesta et al., 2003; Gotz and Barde, 2005). To assess the differentiation potential of Sox $2^{\mathrm{Bgeo/}}$-selected neurospheres, we allowed matrigel-attached single neurospheres to grow in the absence of selection and growth factors for 10 days (Figure $2 \mathrm{E}$ ). GFAP ${ }^{+}$ astrocytes (Figures 2Exix-Xxi) and $\mathrm{TuJ} 1^{+}$neurons (Figures 2Exxiixxiv) were present in all neurosphere cultures. However, in $w t$ and Sox $2^{\text {Bgeo/+ }}$ neurospheres $\mathrm{Tu} 1^{+}$neurons had very short axons (Figures 2Exix,xx), while in So $2^{\text {Bgeo/+ }}$-selected neurospheres TuJ1 ${ }^{+}$ cells had extended axons as typical cortical neurons were present. Our data implies that cells within Sox $2^{\beta g e o /+}$ and Sox $2^{\beta g e o /+}$-selected neurospheres have indeed distinct developmental and differentiation potential.

\section{Sox2 RESTRICTS THE GENERATION OF CRANIAL NCCS FROM CORTICAL NSCs IN VIVO}

Embryonic stem cell-derived Pax6 ${ }^{+}$RG cells can not readily revert to a more primitive type of progenitor and as a result appear to be developmentally restricted (Gotz and Barde, 2005). To assess whether primary So $2^{\mathrm{Bgeo/}}$-selected $\mathrm{Pax}^{+} \mathrm{RG}$ cells behave in a similar manner, we performed heterotopic and heterochronic transplantations into the hindbrains of in vitro cultured mouse and in ovo cultured chick embryos (Figures 3A,B). Transplantations were performed at E8.5 (five somite stage) in mouse embryos and at E1.5 (eight somites) in chick embryos to ensure that the grafted neurospheres were incorporated into the neuroectoderm prior to the earliest waves of NCC formation and migration (Trainor, 2000, 2005; Trainor and Krumlauf, 2000; Basch et al., 2006). Wt, Sox $2^{\beta \mathrm{geo} /+}$, and Sox $2^{\mathrm{Bgeo/}}$-selected neurospheres transplanted into either $\mathrm{r} 2$ or r4 of the hindbrain of both chick (Figures $3 \mathbf{C}-\mathbf{H}$ ) and mouse (Figures 3I-Q) embryos were all incorporated into the neural plate as a cohort of cells with little mixing or intermingling with their immediate neighbors. Remarkably, both $w t$ and Sox $2^{\beta g e o /+}$ neurospheres exhibited consistent abilities to generate migrating NCCs as

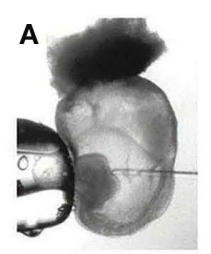

Dil label, graft NSCs
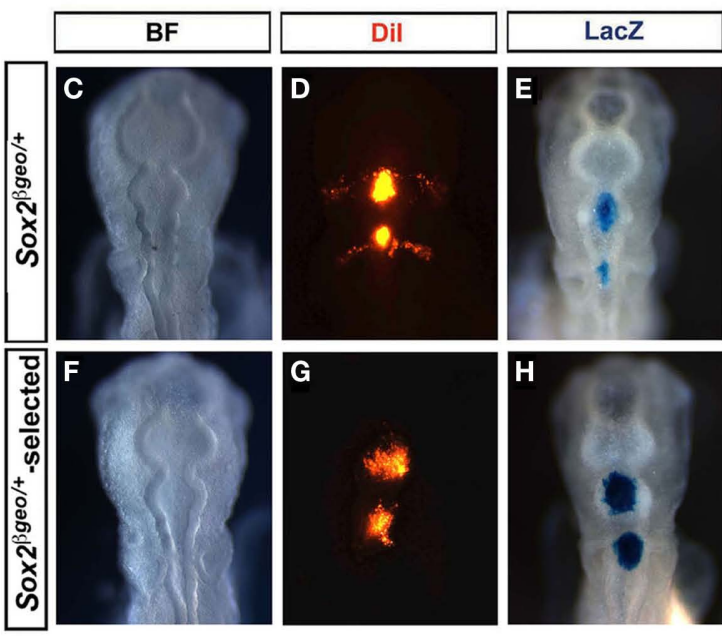

FIGURE 3 | Sox2 restricts NSC commitment to a cranial NCC fate. Neurospheres were transplanted into the hindbrains of mouse and chick embryos (A,B) which were then cultured for up to $36 \mathrm{~h}$. Transplantation of Sox $2^{\text {Bgeo/4 }}$ (C-E) and Sox $2^{\text {Bgeo/4-selected }}$ (F-H) neurospheres into $\mathrm{r} 2$ and $\mathrm{r} 4$ of E1.5 chick embryos. Transplantation of $w t$ (I-K), Sox $2^{\text {Bgeo// }}$ (L-N), and Sox $2^{\text {Bgeo/4- }}$ selected (0-0) neurospheres into $\mathrm{r} 2$ and $\mathrm{r} 4$ of E8.5 mouse embryos.

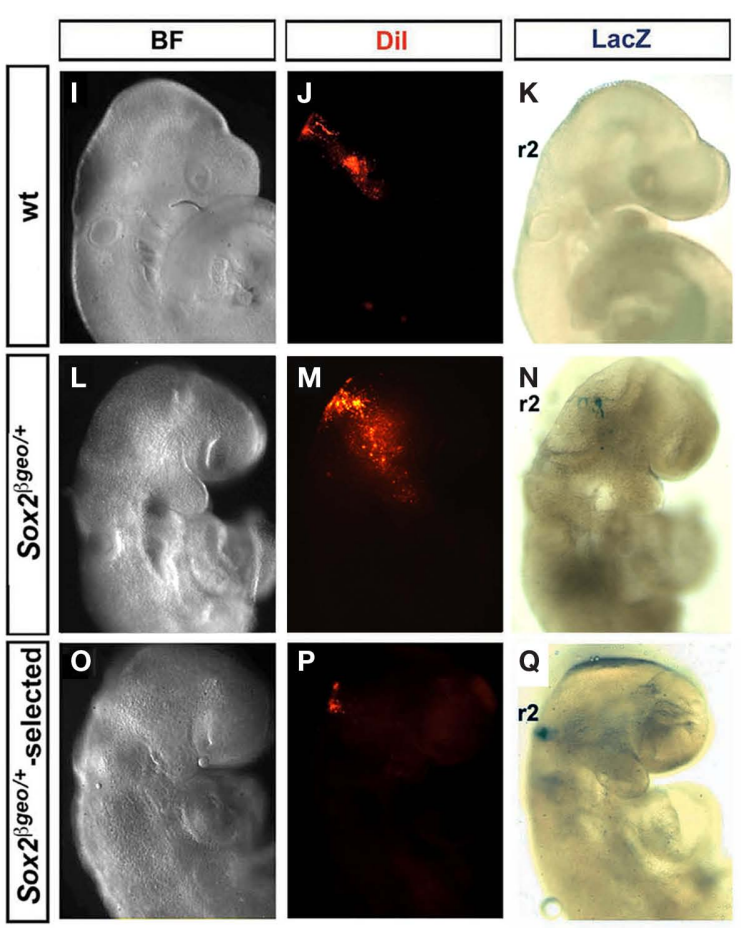

Incorporation into the neural tube, the potential generation of NCCs and the identity of the transplanted cells were determined by Dil labeling (D,G,J,M,P) and $\beta$-galactosidase reporter staining $(\mathbf{E}, \mathbf{H}, \mathbf{K}, \mathbf{N}, \mathbf{Q})$. Compared to $w t(\mathbf{J}-\mathbf{K})$ and Sox $2^{\text {Bgeo/ }}$ (C-E, L-N) neurospheres, which readily generated NCCS, Sox $2^{\text {Bgeo/4- }}$ selected neurospheres (F-H, O-O) exhibited a decreased ability to generate migrating NCCs. 
evidenced by DiI lineage tracing (Figures 3C-E,I-N). Neurospheres transplanted into $\mathrm{r} 2$ in mouse and chick embryos generated substantial numbers of NCCs that colonized the proximo-distal extent of the first branchial arch (Figures 3D,J,M). Similarly, neurospheres transplanted into $\mathrm{r} 4$ in mouse and chick embryos generated substantial numbers of NCCs that colonized the proximo-distal extent of the second branchial arch (Figure 3D). The $w t$ and Sox $2^{\beta g e o / t}$ neurosphere cells respond appropriately to the NCC-inducing signals and migrate ventro-laterally until the first and second pharyngeal arches (Figures 3D,J,M).

The migration pathways adopted by DiI labeled cells derived from the transplanted neurospheres indicated that these cells might be NCCs. To rule out the possibility that the $\mathrm{DiI}^{+}$cells were simply moving passively and being carried along by endogenous NCCs, we used Sox10, a well-known marker of migrating NCCs, to assess the NCC character of the neurosphere-derived cells in the cranial mesenchyme (Figures A1A-C in Appendix). We observed three distinct populations of cells: Sox $10^{+}$endogenous migrating neural cells (green) lateral to the neural tube and underlying the surface ectoderm, Sox $10^{+} \mathrm{DiI}^{+}$cells (orange) and Sox $10^{-} \mathrm{DiI}^{+}$(red) derived from DiI labeled neurospheres transplanted into the hindbrain (Figure A1C in Appendix). The identification of both Sox $10^{+} \mathrm{DiI}^{+}$ (neural derivatives) and Sox10- $\mathrm{DiI}^{+}$(mesenchymal derivatives) reflects the endogenous patterning of NCCs during normal embryonic development. Irrespective of whether neurospheres were transplanted into $\mathrm{r} 2$ or $\mathrm{r} 4$ of the hindbrains of mouse and chick embryos, we identified $\mathrm{DiI}^{+} \mathrm{Tuj} 1^{+}$labeled cells located proximally within the branchial arches and in close proximity to the neural tube which contributed to the formation of the trigeminal (Figures A1D-F in Appendix) and facial ganglia (Figures A1G-I in Appendix) in both species. In contrast, $\mathrm{DiI}^{+} \mathrm{Tuj} 1^{-}$NCCs extensively populated the distal regions of the first and second branchial arches (Figures A1D-I in Appendix). This suggested that migrating cells derived from transplanted neurospheres indeed possess NCC properties. Given the appropriate embryonic niche and exposure to signals therein, E14.5 cortical wt and Sox $2^{\beta g e o /+}$ NSCs could generate cranial NCCs and their typical neural derivatives.

However, when Sox $2^{\beta \text { geo/ } /}$-selected neurospheres were similarly transplanted, we observed the complete absence of any NCC generation (Figures 3F-H,O-Q). This suggested that Sox2 expression inhibits the generation of NSC-derived cranial NCCs. To test this notion, we overexpressed mouse Sox 2 in the neuroepithelium of E1.5 chick embryos (Figure A2 in Appendix). Whereas control GFP plasmid was continually expressed in migrating NCCs (Figures A2A,B in Appendix), neuroepithelial cells overexpressing Sox2 (Figures A2C-G in Appendix), failed to delaminate and migrate, remaining within the neural tube. NCC-specific Sox10 staining (Figures A2H,I,J in Appendix) revealed significantly fewer migrating NCCs on the Sox2 electroporated side and cranial ganglia reduced in size when compared to the control side (Figures A2I,J in Appendix). We concluded that Sox2 inhibited the generation of NCCs by restricting NSC differentiation. To test if transition from a Sox $2^{+}$; Sox $9^{-}$state to a Sox $2^{-}$; So $x 9^{+}$state was required for NSC differentiation into NCCs, we overexpressed mouse Sox9 in E1.5 chick cranial neural tubes and observed enhanced NCC generation and consequently enlarged cranial ganglia (Figures $\mathbf{A} 2 \mathbf{K}-\mathbf{O}$ in Appendix). Therefore, as NSCs differentiate into NCCs, there is a clear switch in Sox expression state with Sox2 inactivated in the NCC progenitors, whereas Sox 9 and then Sox 10 activated in newly migrating NCCs (Melton et al., 2004).

\section{DISCUSSION}

Cortical neurospheres are heterogeneous free-floating aggregates consisting of mixed populations of NSC, NP, and differentiated cells that eventually lose their regional identity in culture. Here, we describe, for the first time, a unique way of generating homogenous neurospheres with spatio-temporal identity that resembles the in vivo profile of proliferating cells in the embryonic cortex. Our results confirm and significantly extend previous findings by showing that Sox2 is not only important for NSC self-renewal (Zappone et al., 2000; Ferri et al., 2004; Favaro et al., 2009; Pevny and Nicolis, 2010), but also for maintaining the cortical Pax6 ${ }^{+}$ identity and properties of RG cells ex vivo. Our results also show that maintenance of Sox 2 expression prevents the NSC progression into committed NPs and differentiated cells. This is particularly evident in the Sox $2^{\beta g e o /+}$-selected neurospheres, where the absence of Sox $2^{-}$Sox $9^{+}$cells prevents progression to lineage-committed NPs and when these selected neurospheres are transplanted they cannot respond readily to local signals to differentiate unless they downregulate Sox2. This may reflect the normal progression of NSCs in the embryo (Pevny and Placzek, 2005) and highlights the balance required between a Sox 2 -mediated intrinsic program versus one dictated by the surrounding extrinsic signals considered to constitute the stem cell niche environment. The differences in properties between homogenous and heterogeneous neurospheres implies that in heterogeneous neurospheres, which consist of a mixed population of Sox $2^{+} / \mathrm{Sox}^{-} \mathrm{NSC}$ and Sox $2^{-} / \mathrm{Sox}^{+} \mathrm{NPs}$ that are capable of generating NCCs upon back-transplantation into avian and mouse embryonic hindbrains, that it is the progenitor cells that impact significantly on the patterning of NSCs. Hence, not only is Sox 2 important for the cellular memory of cortical NSCs, but also as a cell intrinsic regulator of NSC plasticity.

Cranial NCCs are a transient migratory population that exhibit a significant degree of plasticity and differentiation fates, particularly in their numerous cell and tissues contributions in the vertebrate head (Trainor and Krumlauf, 2000). NCCs are induced to form transiently at the junction between the neuroepithelium and adjacent ectoderm by the specific interplay of distinct signals from these tissues (Selleck and Bronner-Fraser, 1995) between E8.5 and E9.5 of embryonic development in mouse and between E1.5 and E2.5 in chick. These cells migrate in distinct segregated streams from the neural tube into the adjacent pharyngeal arches (Tam, 1998). Given the transient nature of NCC induction and migration from primitive neuroepithelium, which is prior to the major period or neuroepithelial maturation, it was considered highly unlikely that cranial neural crest precursor cells would persist in or could be generated from the cortex of E14.5 embryos. Our data however suggests this is indeed the case and interestingly, neural crest precursor cells have recently been shown to persist even throughout adult life in mouse whisker hair follicles (Sieber-Blum et al., 2004).

A key issue in stem cell biology is how distinct derivatives are generated from stem cell populations by a balance between cell intrinsic and cell extrinsic cues. Similar issues have been the 
focus of the NCC field However, the transition of a Sox $2^{+}$; Sox $9^{-}$ neural stem cell into a Sox $2^{-}$; Sox $9^{+}$differentiating cell appears to be generally conserved throughout embryonic neurogenesis. Not only is this mechanism important during cortical neurogenesis at E14.5 as we have shown, but a similar transition appears to occur during the transformation of neural stem cells into neural crest cells at E8.5 (Trainor and Krumlauf, 2001; Cheung and Briscoe, 2003). In support of this idea, it has been suggested that downregulation of Sox2 in concert with Sox9 (Cheung and Briscoe, 2003; Cheung et al., 2005) up-regulation is required as part of a complex mechanism to generate neural crest cells from neural stem cells in avian embryos (Wakamatsu et al., 2004). Furthermore, Sox9 was shown to antagonize Sox2, and more importantly Sox9 was also demonstrated to be required for trunk NCC formation (Wakamatsu et al., 2004; Wegner and Stolt, 2005). Interestingly, this reflects the properties of $S o x 2^{\beta \text { Bgeo/ }}$ neurospheres and implies that neural stem cells within the cortex may retain and endogenous capacity to generate neural crest cells if provided with the appropriate environment.

The generation of NCCs from wild type and Sox $2^{\text {Bgeo/t }}$ neurospheres was surprising and significant since the transplanted cells were derived from the cortex of E14.5 embryos, which is nearly a week of gestation beyond the transient window of endogenous NCC formation and migration. This indicates the importance of Sox2-Sox9 signaling mechanisms in the regulation of neural stem cell maintenance and differentiation (Scott et al., 2010), but it also highlights their reiterative use throughout multiple stages of embryonic neurogenesis. Moreover, our results provocatively imply that the developmental segregation of the CNS and neural crest may be reversible even over extended periods of time. In support of this idea, migrating chick NCCs in an E2.5 embryo have been transplanted back into the ventral neural tube of younger E1.5 chick embryos. In doing so the NCCs were able to generate ventral motor neuron cell types, which are not typical NCC derivatives (Ruffins et al., 1998) lending further weight to the inherent plasticity of NCCs and the reversibility between NCCs and neuroepithelium. Lastly the differences in properties

\section{REFERENCES}

Ahmed, S. (2009). The culture of neural stem cells. J. Cell. Biochem. 106, 1-6.

Avilion, A. A., Nicolis, S. K., Pevny, L. H., Perez, L., Vivian, N., and Lovell-Badge, R. (2003). Multipotent cell lineages in early mouse development depend on SOX2 function. Genes Dev. 17, 126-140.

Basch, M. L., Bronner-Fraser, M., and Garcia-Castro, M. I. (2006). Specification of the neural crest occurs during gastrulation and requires Pax7. Nature 441, 218-222.

Brazel, C. Y., Limke, T. L., Osborne, J. K., Miura, T., Cai, J., Pevny, L., and Rao, M. S. (2005). Sox 2 expression defines a heterogeneous population of neurosphere-forming cells in the adult murine brain. Aging Cell 4, 197-207.

Bylund, M., Andersson, E., Novitch, B. G., and Muhr, J. (2003). Vertebrate neu-

between homogenous and heterogenous neurospheres imply that in heterogeneous neurospheres, the progenitor cells impact significantly on the patterning of NSCs.

Irrespective of whether neurospheres are grown in the presence or absence of selective pressure for Sox2 expression, both populations contain Sox $2^{+}$NSCs. The failure of homogeneous Sox $2^{+}$neurospheres to generate NCCs implies that Sox $2^{+}$NSCs are difficult to reprogram when cultured in the absence of their niche provided by their associated progenitors or differentiated cells. This also implies that the Sox $2^{+}$NSC-derived Sox ${ }^{-}$NP cells could be the ones that predominantly give rise to NCCs in response to environmental signals provided by the local environment in the graft site of the embryo. Overall, our results highlight the flexibility of NSCs and the balance required between a Sox2-mediated intrinsic program to preserve the cellular memory of cortical NSCs and another one to regulate NSC plasticity, dictated by their niche.

\section{ACKNOWLEDGMENTS}

We thank S. Pagakis and K. Sullivan for advice on confocal microscopy; C. Atkins for FACS analysis; and S. Guioli for the Sox 9 antibody. Eumorphia Remboutsika was supported by a TMR Network-funded Fellowship (EU), by the Medical Research Council (MRC; UK) and currently by the General Secretariat for Research and Technology (GSRT; ENTER-01EP67, EPAN-B26, 05NON-EU82; Greece) and the Research Promotion Foundation (Grant 7396; Cyprus). Paul A. Trainor is supported by the Stowers Institute for Medical Research, the National Institute of Dental and Craniofacial Research (Grant R01 DE 016082), and a March of Dimes Basil O'Connor scholar award (USA). Robin Lovell-Badge and Cynthia L. Andoniadou are supported by the Medical Research Council (UK; MRC file reference U117512772). Cynthia L. Andoniadou was also supported by the Beddington Fund. Maximilianos Elkouris was supported by grant 05NON-EU82 (GSRT-Greece) and an "Alexander Fleming" Fellowship (Greece). Maria Poulou was supported by PENED 03ED394 (GSRT-Greece). Angelo Iulianella was supported by a Canadian Institute of Health Research Fellowship. Thimios A. Mitsiadis was financed by funds from the University of Zurich (UZH).

Lovell-Badge, R., and Episkopou, V. (2005). Neuronal migration and ventral subtype identity in the telencephalon depend on SOX1. PLoS Biol. 3, e186. doi: 10.1371/journal. pbio.0030186

Elkouris, M., Balaskas, N., Poulou, M., Politis, P.K., Panayiotou, E., Malas, S., Thomaidou, D., and Remboutsika, E. (2011). Soxl maintains the undifferentiated state of cortical neural progenitor cells via the suppression of Prox1-mediated cell cycle exit and neurogenesis. Stem Cells 29, 89-98.

Ellis, P., Fagan, B. M., Magness, S. T., Hutton, S., Taranova, O., Hayashi, S., Mcmahon, A., Rao, M., and Pevny, L. (2004). SOX2, a persistent marker for multipotential neural stem cells derived from embryonic stem cells, the embryo or the adult. Dev. Neurosci. 26, 148-165.
Favaro, R., Valotta, M., Ferri, A. L., Latorre, E., Mariani, J., Giachino, C., Lancini, C., Tosetti, V., Ottolenghi, S., Taylor, V., and Nicolis, S. K. (2009). Hippocampal development and neural stem cell maintenance require Sox2-dependent regulation of Shh. Nat. Neurosci. 12, 1248-1256.

Ferri, A. L., Cavallaro, M., Braida, D., Di Cristofano, A., Canta, A., Vezzani, A., Ottolenghi, S., Pandolfi, P. P., Sala, M., Debiasi, S., and Nicolis, S. K. (2004). Sox2 deficiencycausesneurodegeneration and impairedneurogenesis in theadultmouse brain. Development 131, 3805-3819.

Gotz, M. (2003). Glial cells generate neurons-master control within CNS regions: developmental perspectives on neural stem cells. Neuroscientist 9 , 379-397.

Gotz, M., and Barde, Y. A. (2005). Radial glial cells defined and major 
intermediates between embryonic stem cells and CNS neurons. Neuron 46, 369-372.

Gotz, M., Hartfuss, E., and Malatesta, P. (2002). Radial glial cells as neuronal precursors: a new perspective on the correlation of morphology and lineage restriction in the developing cerebral cortex of mice. Brain Res. Bull. 57, 777-788.

Gotz, M., Stoykova, A., and Gruss, P. (1998). Pax6 controls radial glia differentiation in the cerebral cortex. Neuron 21, 1031-1044.

Graham, V., Khudyakov, J., Ellis, P., and Pevny, L. (2003). SOX2 functions to maintain neural progenitor identity. Neuron 39, 749-765.

Jensen, J. B., and Parmar, M. (2006). Strengths and limitations of the neurosphere culture system. Mol. Neurobiol. 34, 153-161.

Kamachi, Y., Uchikawa, M., and Kondoh, H. (2000). Pairing SOX off: with partners in the regulation of embryonic development. Trends Genet. 16, 182-187.

Kan, L., Israsena, N., Zhang, Z., Hu, M., Zhao, L. R., Jalali, A., Sahni, V., and Kessler, J.A. (2004). Sox1 acts through multiple independent pathways to promote neurogenesis. Dev. Biol. 269, 580-594.

Kriegstein, A. R., and Gotz, M. (2003). Radial glia diversity: a matter of cell fate. Glia 43, 37-43.

Li, M., Pevny, L., Lovell-Badge, R., and Smith, A. (1998). Generation of purified neural precursors from embryonic stem cells by lineage selection. Curr. Biol. 8, 971-974.

Machon, O., Backman, M., Krauss, S., and Kozmik,Z. (2005). The cellular fate of cortical progenitors is not maintained in neurosphere cultures. Mol. Cell. Neurosci. 30, 388-397.

Malas, S., Postlethwaite, M., Ekonomou, A., Whalley, B., Nishiguchi, S., Wood, H., Meldrum, B., Constanti, A., and Episkopou, V. (2003). Sox1-deficient mice suffer from epilepsy associated with abnormal ventral forebrain development and olfactory cortex hyperexcitability. Neuroscience 119, 421-432.
Malatesta, P., Hack, M. A., Hartfuss, E., Kettenmann, H., Klinkert, W., Kirchhoff, F., and Gotz, M. (2003). Neuronal or glial progeny: regional differences in radial glia fate. Neuron 37, 751-764.

Malatesta, P., Hartfuss, E., and Gotz, M. (2000). Isolation of radial glial cells by fluorescent-activated cell sorting reveals a neuronal lineage. Development 127, 5253-5263.

Melton, K. R., Iulianella, A., and Trainor, P. A. (2004). Gene expression and regulation of hindbrain and spinal cord development. Front. Biosci. 9, 117-138.

Mori, T., Buffo, A., and Gotz, M. (2005). The novel roles of glial cells revisited: the contribution of radial glia and astrocytes to neurogenesis. Curr. Top. Dev. Biol. 69, 67-99.

Nishiguchi, S., Wood, H., Kondoh, H., Lovell-Badge, R., and Episkopou, V. (1998). Sox1 directly regulates the gamma-crystallin genes and is essential for lens development in mice. Genes Dev. 12, 776-781.

Pevny, L., and Placzek, M. (2005). SOX genes and neural progenitor identity. Curr. Opin. Neurobiol. 15, 7-13.

Pevny, L. H., and Nicolis, S. K. (2010). Sox2 roles in neural stem cells. Int. J. Biochem. Cell Biol. 42, 421-424.

Rizzoti, K., Brunelli, S., Carmignac, D., Thomas, P. Q., Robinson, I. C., and Lovell-Badge, R. (2004). SOX3 is required during the formation of the hypothalamo-pituitary axis. Nat. Genet. 36, 247-255.

Ruffins, S., Artinger, K. B., and BronnerFraser, M. (1998). Early migrating neural crest cells can form ventral neural tube derivatives when challenged by transplantation. Dev. Biol. 203,295-304.

Sandberg, M., Kallstrom, M., and Muhr, J. (2005). Sox 21 promotes the progression of vertebrate neurogenesis. Nat. Neurosci. 8, 995-1001.

Scaffidi, P., and Bianchi, M. E. (2001). Spatially precise DNA bending is an essential activity of the sox 2 transcription factor. J. Biol. Chem. 276, 47296-47302.

Scott, C. E., Wynn, S. L., Sesay, A., Cruz, C., Cheung, M., Gomez Gaviro, M.V.,
Booth, S., Gao, B., Cheah, K. S., LovellBadge, R., and Briscoe, J. (2010). SOX9 induces and maintains neural stem cells. Nat. Neurosci. 13, 1181-1189.

Selleck, M. A., and Bronner-Fraser, M. (1995). Origins of the avian neural crest: the role of neural plate-epidermal interactions. Development 121 , 525-538.

Sieber-Blum, M., Grim, M., Hu, Y. F., and Szeder, V. (2004). Pluripotent neural crest stem cells in the adult hair follicle. Dev. Dyn. 231, 258-269.

Sturm, K., and Tam, P. P. (1993). Isolation and culture of whole postimplantation embryos and germ layer derivatives. Meth. Enzymol. 225, 164-190.

Tam,P.P.(1998). Postimplantation mouse development: whole embryo culture and micro-manipulation. Int. J. Dev. Biol. 42, 895-902.

Trainor, P., and Krumlauf, R. (2000). Plasticity in mouse neural crest cells reveals a new patterning role for cranial mesoderm. Nat. Cell Biol. 2, 96-102.

Trainor, P. A. (2000). Craniofacial morphogenesis: a meeting in memory of Peter Thorogood. Bioessays 22, 202-204.

Trainor,P.A. (2005).Specification of neural crest cell formation and migration in mouse embryos. Semin. Cell Dev. Biol. 16, 683-693.

Trainor, P. A., and Krumlauf, R. (2001) Hox genes, neural crest cells and branchial arch patterning. Curr. Opin. Cell Biol. 13, 698-705.

Wakamatsu, Y., Endo, Y., Osumi, N., and Weston, J. A. (2004). Multiple roles of Sox2, an HMG-box transcription factor in avian neural crest development. Dev. Dyn. 229, 74-86.

Wegner, M., and Stolt, C. C. (2005). From stem cells to neurons and glia: a Soxist's view of neural development. Trends Neurosci. 28, 583-588.

Wilkinson, D. G. (1995). RNA detection using non-radioactive in situ hybridization. Curr. Opin. Biotechnol. 6, 20-23.

Wilkinson, D. G., and Nieto, M.A. (1993). Detection of messenger RNA by in situ hybridization to tissue sections and whole mounts. Methods Enzymol. 225, 361-373.
Wilson, M., and Koopman, P. (2002). Matching SOX: partner proteins and co-factors of the SOX family of transcriptional regulators. Curr. Opin. Genet. Dev. 12, 441-446.

Wood, H. B., and Episkopou, V. (1999). Comparative expression of the mouse Sox 1 , Sox 2 and Sox 3 genes from pregastrulation to early somite stages. Mech. Dev. 86, 197-201.

Zappone, M. V., Galli, R., Catena, R., Meani, N., De Biasi, S., Mattei, E., Tiveron, C., Vescovi, A. L., LovellBadge, R., Ottolenghi, S., and Nicolis, S. K. (2000). Sox2 regulatory sequences direct expression of a (beta)-geo transgene to telencephalic neural stem cells and precursors of the mouse embryo, revealing regionalization of gene expression in CNS stem cells. Development 127, 2367-2382.

Zhao, S., Nichols, J., Smith, A. G., and Li, M. (2004). SoxB transcription factors specify neuroectodermal lineage choice in ES cells. Mol. Cell. Neurosci. 27, 332-342.

Conflict of Interest Statement: The authors declare that the research was conducted in the absence of any commercial or financial relationships that could be construed as a potential conflict of interest.

Received: 09 March 2011; paper pending published: 18 March 2011; accepted: 28 March 2011; published online: 11 April 2011.

Citation: Remboutsika E, Elkouris $M$, Iulianella A, Andoniadou CL, Poulou M, Mitsiadis TA, Trainor PA and LovellBadge R (2011) Flexibility of neural stem cells. Front. Physio. 2:16. doi: 10.3389/ fphys.2011.00016

This article was submitted to Frontiers in Craniofacial Biology, a specialty of Frontiers in Physiology.

Copyright ( 2011 Remboutsika, Elkouris, Iulianella, Andoniadou, Poulou, Mitsiadis, Trainor and Lovell-Badge. This is an openaccess article subject to a non-exclusive license between the authors and Frontiers Media $S A$, which permits use, distribution and reproduction in other forums, provided the original authors and source are credited and other Frontiers conditions are complied with. 


\section{APPENDIX}
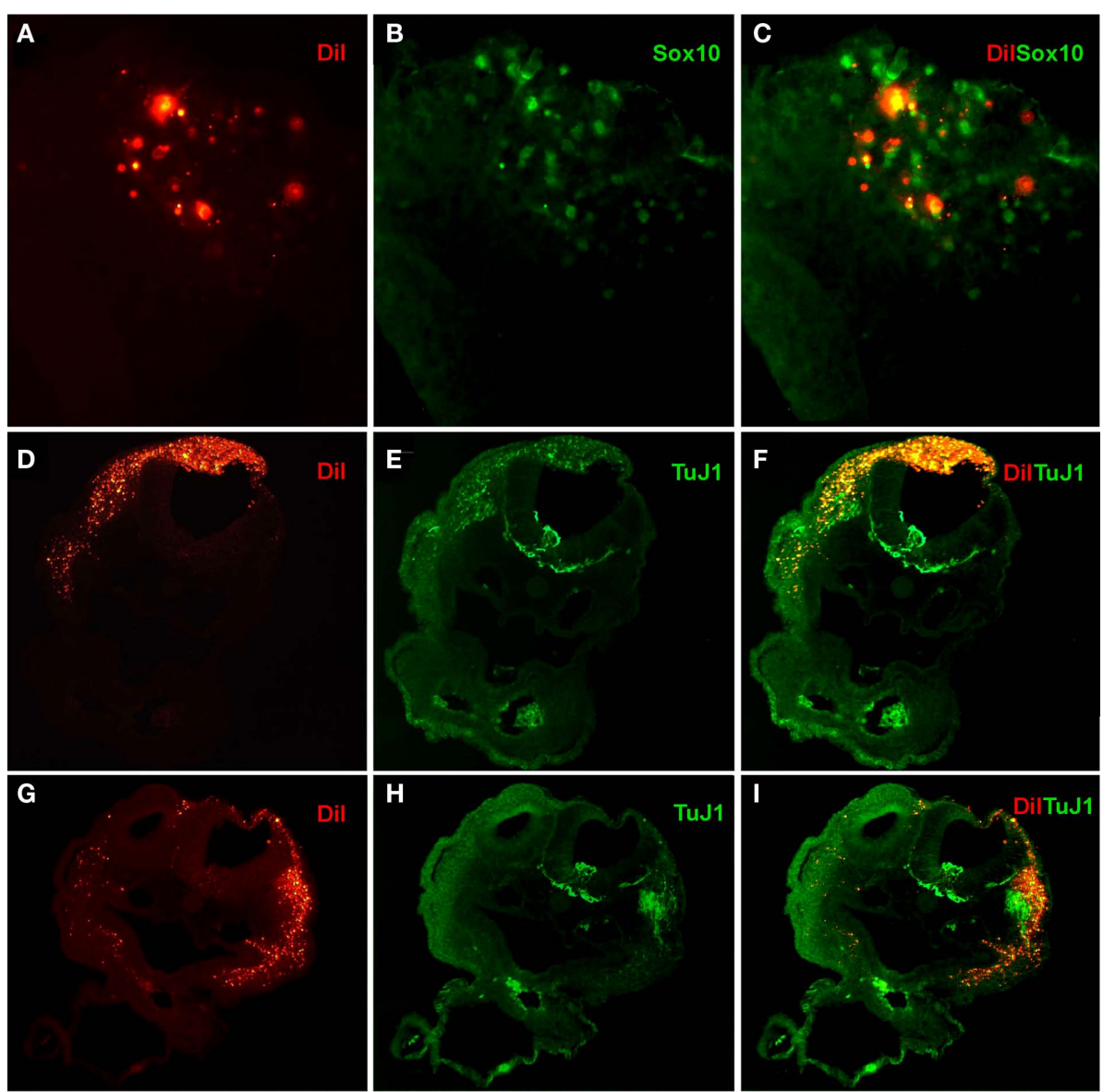

H

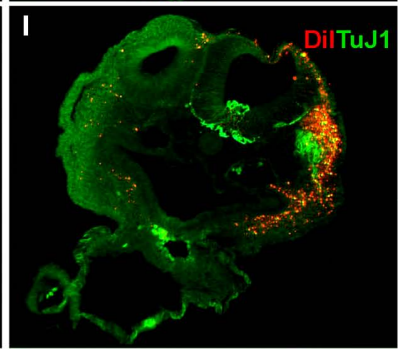

FIGURE A1 | Differentiation of NSC-derived cranial NCCs. Transplanted Dil labeled Sox $2^{\text {Bgeo/ }}$ neurospheres give rise to migrating NCCs (A) as evidenced by Dil labeling in cryosections of host embryos cultured for $24 \mathrm{~h}$ in ovo. Sox 10 immunostaining (B) not only labels endogenous migrating NCCs but also many Dil labeled migrating cells derived from the transplanted neurospheres, confirming their NCC identity (C). Neurospheres transplanted into r2 and r4 give rise to migrating NCCs as evidenced by Dil labeling $(\mathbf{D}, \mathbf{G})$ which colonize the entire proximo-distal extent of the first and second branchial arches respectively $(\mathbf{D}, \mathbf{G})$. Tuj1 immunostaining $\mathbf{( E , H )}$ revealed the neurogenic potential of neurosphere-derived NCCs by demonstrating that a subpopulation of the proximally located cells contribute to the trigeminal (D-F) and facial (G-I) ganglia respectively. 

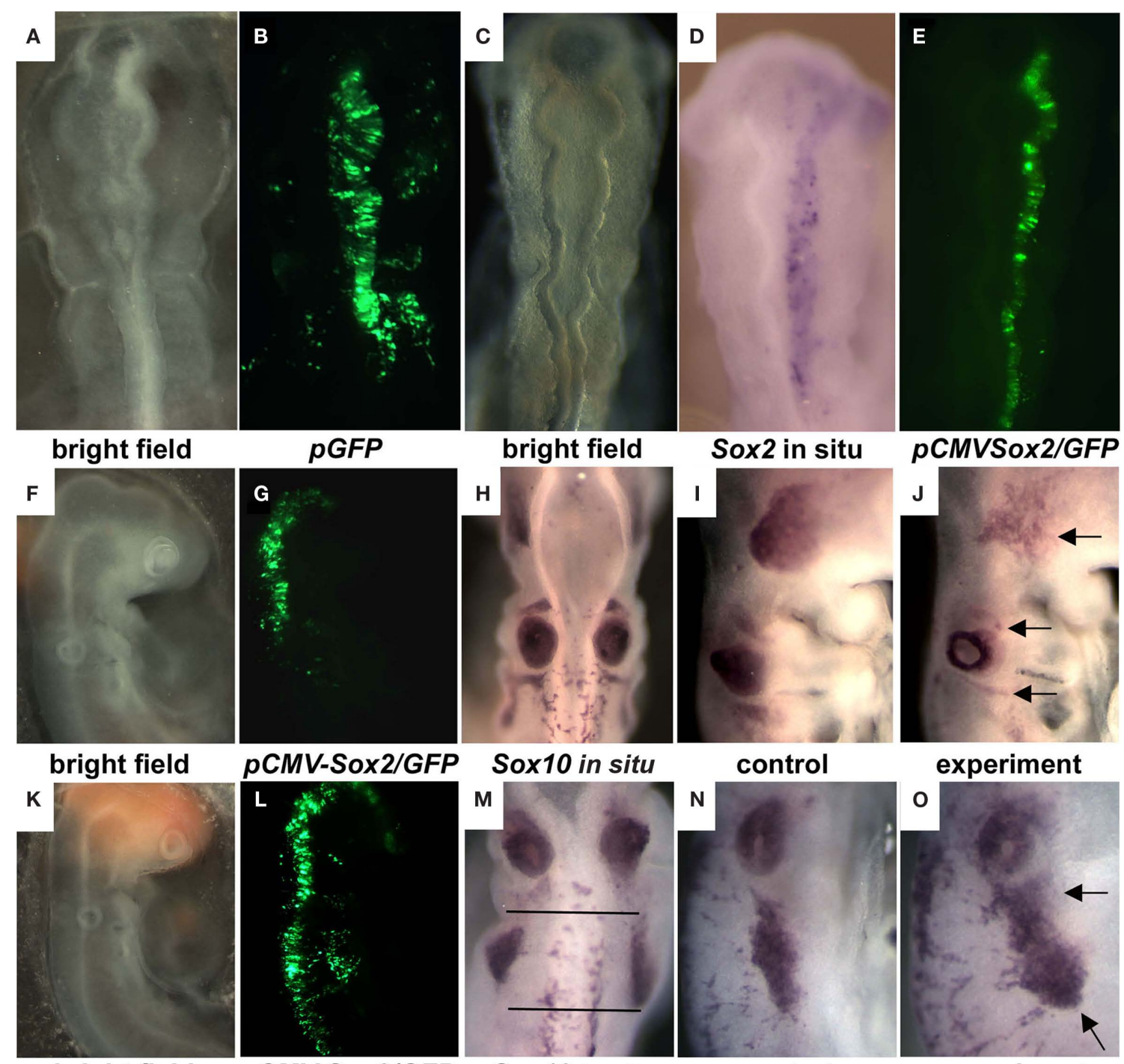

pCMV-Sox2/GFP
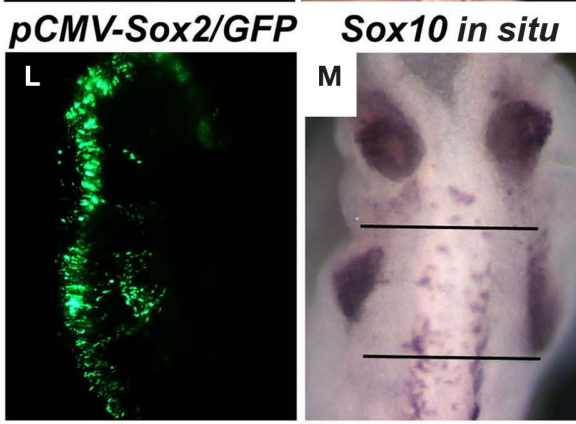

bright field
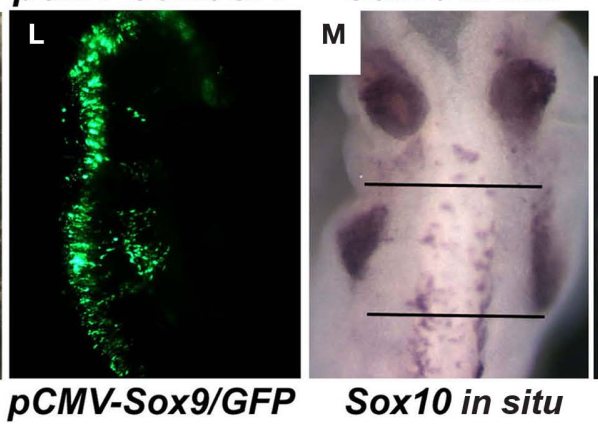

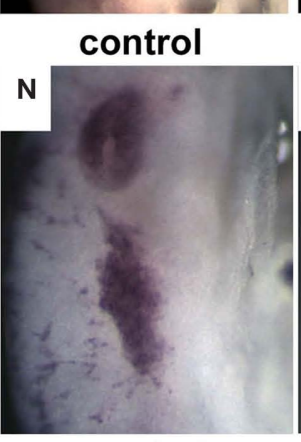

control

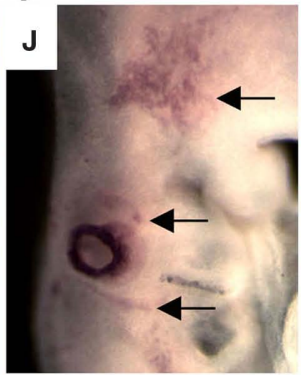

experiment

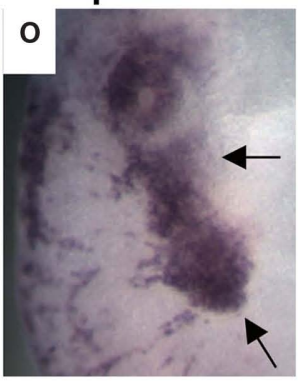

experiment
FIGURE A2 | Sox2 restricts neuroepithelial differentiation into NCCs. Electroporation of a control pCMV-GFP plasmid into the cranial neural tube of a 1.5-day chick embryo (A) labels one side of the neural tube and its derived migrating NCCs (B). In contrast, electroporation of pCMV-Sox2/pCMV-GFP into the cranial neural tube of a 1.5 day chick embryo (C) leads to the overexpression of Sox2 (D) and labeling of one side of the neural tube but these labeled cells are unable to give rise to migrating NCCs (E). Overexpressing pCMV-Sox2/pCMV-
GFP in the neural tube of chick embryos (F-J) restricts the generation of NCCs on the electroporated side [arrows in (J)] as evidenced by dorsal $\mathbf{( H )}$ and lateral views (I,J) of Sox10 in situ hybridization staining of migrating NCCs after $24 \mathrm{~h}$ in ovo culture. In contrast, overexpression of Sox9 on one side of the cranial neural tube by electroporation of pCMV-Sox9/pCMV-GFP (K-O) enhances the production of NCCs, as evidenced by dorsal $(\mathbf{M})$ and lateral views $(\mathbf{N}, \mathbf{O})$ of Sox 10 in situ hybridization staining of migrating NCCs after $24 \mathrm{~h}$ in ovo culture. 